\title{
Recent Trends in Institutional Confidence Among Arkansans: Updating Earlier Findings
}

\author{
ROBERT L. SAVAGE \\ WILLIAM R. DARDEN \\ University of Arkansas-Fayetteville
}

In a study reporting on regional differences in public opinion among Arkansans in 1982, Savage and Blair (1984: 65) assert "that more altruistic, less remote, and more decentralized institutions receive stronger votes of confidence." Data from a 1984 survey of Arkansans do not contradict that assertion but do allow an assessment of trends in public confidence among citizens of the state during the early 1980's as well as affording comparisons with confidence trends in the nation as a whole and in a sister state located in the industrial northeast.

Recent analyses of American public opinion on confidence or trust in various institutions typically suggest a modest trend of increasingly favorable perceptions. ${ }^{1}$ These studies, on the other hand, generally show that different levels of confidence are exhibited by various groups or categories of respondents, for example, the more distrustful perceptions of the national government held by black Americans ("Public More Trusting," 1983: 2). The reports on public confidence in institutions rarely, however, address regional differences across the nation. Is confidence in churches higher in the South where fundamentalist Protestantism prevails? Is the Presidency more esteemed in the West during these days of the Reagan administration?

The study reported here does not directly deal with such regional differences nor generally, for that matter, with perceptions of national institutions. Still, the latest findings of a continuing survey of Arkansans' confidence in state institutions does address the temporal trend in a more localized context. Moreover, the release of recent comparable findings of a New Jersey survey make possible some assessment of regional differences in perceptions of a few institutions at the state level.

\section{The AHRP Longitudinal Survey Of Institutional Confidence}

As often happens in social science research, the longitudinal survey of institutional confidence among Arkansans by the Arkansas Household Research Panel (AHRP) began quite innocently as a part of a larger study in 1980 focusing on the images of banks as social institutions. 2 Two years later, similar questions were of concern in study dealing more largely with political ideology and perceptions of the institutional fabric of political life in Arkansas. ${ }^{3}$ In 1984 the question of institutional confidence prevailed in its own right because of the valuable opportunity for longitudinal comparison.

The 1984 survey on confidence used scales identical to those of the 1982 study. As will become apparent, these later surveys used a modified and expanded version of the 1980 survey items. ${ }^{4}$ The scales ask respondents to indicate if they have "a great deal of," "only some," or "hardly any" confidence in a dozen different 


\section{Recent 'Trends in Institutional Confidence}

institutions (ten in 1980). The rated institutions include social, economic, and political ones.

The 1984 survey was conducted during April by the AHRP in a mail survey sent to its continuing panel of randomly selected households across the state. While poorer, less well-educated respondents are underrepresented in such surveys, we do not find significant, consistent differences in perceptions of institutions across educational or income levels in our sample. Moreover, it is not the case, as might be expected, that the more advantaged AHRP sample is more positive toward institutions than is typical of national samples. 5 This assertion leads directly to our substantive conclusions.

\section{An Increase In Confidence or Just Bottoming Out? Arkansas and the Nation}

By the time of the 1982 survey of Arkansans' confidence in their state institutions, national studies had been reporting that the decline in confidence in institutions associated with the Watergate period (ca. 1974) was finally bottoming out (Shaver, 1980). The state survey, however, exhibited at least small declines in the number of respondents indicating "a great deal of confidence" in eight of nine comparable institutions. Moreover, for six of these nine institutions, the number indicating "hardly any confidence" was higher in 1982 than in 1980. Decline, then, rather than bottoming out, was still the trend in Arkansas.

In 1984, national analysts are now at least cautiously pointing to increasing confidence in institutions. The 1984 survey of Arkansans, as shown in Table 1, reflects at best only a bottoming out of the decline. For twelve institutions, seven exhibit small decreases in the number indicating "a great deal of confidence" from the 1982 levels. The largest change, indeed, is in the positive direction, from $7.8 \%$ to $13.9 \%$, for utilities. As the only other increase greater than one percentage point in this later period is for the Office of the Governor, one might well question whether the decline is really over in Arkansas. Certainly, for the nine institutions for which there is comparable data, only the Office of the Governor has risen about its 1980 level.

Bottoming out is suggested, however, in the figures reported in Table 1 (at end of paper) for the percent indicating "hardly any" confidence. These percentages were smaller in 1984 than in 1982 for eight of the twelve institutions. Moreover, for three of these institutions -- utilities, oil companies, and Office of the Governor -- the change was a dramatic one of twelve percentage points or more fewer people giving the most negative rating. In fact, over the four-year period, seven of the nine comparable institutions exhibited decreases in the number of respondents indicating "hardly any" confidence. Thus, while Arkansas institutions have not risen to their 1980 level for "a great deal of" confidence, most of them seem to have regained at least some confidence that Arkansans previously endowed in them. 6

The most compelling finding, however, is the general one that Arkansans' moods still lag behind those of the nation. In 1982, Arkansans' confidence in state institutions was still declining and only in 1984 is there evidence that the decline has bottomed out. For the nation the same period shows movement from a bottoming out to at least a mild increase in public confidence. It is tempting to point to the state's tendency to lag behind the nation on so many socioeconomic indicators but the correlation of public "moods" with general socioeconomic conditions is a tenuous one at best. 


\section{Robert L. Savage and William R. Darden}

\section{Consistency Across The Board or CancelingOut? Institutional Comparisons}

Some of the exceptional instances noted above demonstrate that popular perceptions have not changed uniformly for all institutions. The more pertinent question, however, is whether the levels of confidence have changed in ways that alter the relative rankings of institutions. Indeed, such relative rankings persisted in national polls through the post- watergate decline (e.g., churches/organized religion ranked at or near the top; Congress ranked very low). Indeed, for the comparable institutions, little change occurred in the Arkansas rankings between 1980 and 1982. A related question is the matter of differential change for particular categories or types of institutions regardless of their rankings.

Answers to both questions are facilitated if the percentages across the three ratings for each institution can be collapsed to a single weighted scalar value of "score". While any assumption of equal distance between the three ratings is dubious, nonetheless it seems reasonable and certainly facilitates comparison to devise a weighted score which rewards those institutions in which sizable numbers of persons place "a great deal of" confidence and at the same time penalize institutions for which many people regard as deserving "hardly any" confidence. Such a scoring system is to double the percentage of respondents replying "a great deal of" confidence, and divide the total by two. The maximum possible score, then, is 100 , the hypothetical value that would be obtained if all respondents rated an institution with "a great deal of" confidence. This weighted scoring scheme allows a more direct ranking of the institutions inasmuch as it accounts for lower ratings (or no response) as well as the highest rating.

Table 2 (at end of paper) shows the weighted scores and rankings for the twelve institutions rated in 1982 and 1984. The top six institutions not only retain their top rankings in 1984 but also exhibit remarkably little change in their weighted scores. The only change in these rankings is that newspapers are tied with television news for fifth place in the later year, a tie actually produced by a slight decline in confidence for television news. There are several switches in rank among the bottom six institutions but none of these changes reflect movement greater than two ranks.

On the other hand, there are some notable changes in the weighted scores. These changes are simply reflections of the exceptional instances noted above. Thus the scores for Office of the Governor, utilities, and oil companies have dramatically increased. At the same time, there has been a sharp decrease for confidence in local government. Why these changes? For the two economic institutions perhaps the stabilization of the world oil market has been a factor but the greater increase for confidence in utilities clouds that assertion somewhat. However, rising utility rates for consumers, the considerable media coverage of controversies surrounding practices of utilities, and the rhetoric of political candidates in the early stages of the primary campaign may have produced the sharply critical perceptions of 1982 . The emergence of a strongly consumer-oriented Public Service Commission with the commissioner appointments of Governor Clinton may have had the effect of enhancing images of the utilities.

As for the Office of the Governor, the change is no great surprise. While we had originally hoped for an institutional measure here, there is probably no way to separate the office from the incumbent. Thus, Bill Clinton in 1984 appears to not only inspire greater confidence than Frank White in 1982, but also Bill Clinton in 1980. Former Governor White, after all, drew considerable media attention for a number of actions hardly likely to promote confidence such as his admissions of signing legislation without reading it previously. And, the young, ambitious Bill Clinton of 1980, perhaps stepped on too many toes in his broad array of policy goals. 
In any event, the 1984 Clinton has greatly improved public estimation of the Office of the Governor.

The lowered estimation of local government in the two-year period is perhaps even more mysterious than the rising esteem for utilities. There is traditionally considerable regional variation for public confidence in local government but this variability does not offer any definite clues for a decline of such proportions statewide (Savage and Blair, 1984). The only statewide phenomenon touching upon the local level the past two years has been the controversy surrounding public education, and it is by no means clear that citizens strongly link "local government" with the schools. On the other hand, many local governments have had local referenda on new taxes under recent changes in state law, and these elections in scattered jurisdictions may have had a cumulative impact on the aggregate perception of local governments. This remains a highly speculative judgment as we are unable to partition the data for a test.

To return to larger considerations, however, Arkansans exhibit very marked stability in their assessment of the relative status of institutions, at least with regard to the degree of confidence to be placed in those institutions. Moreover, such changes as have occurred in these relative rankings exhibit no underlying patterns with some changes reflecting the fortunes of a larger world stage or reversals of leadership. Other changes simply remain mysteries at present whatever our speculations about recent Arkansas history.

\section{The Same All Over or Different Strokes For Different Folks? Comparisons With New Jersey}

In February, 1984, the Eagleton Institute of Politics at Rutgers University conducted a statewide telephone poll of $804 \mathrm{New}$ Jerseyans for which confidence in a somewhat similar array of institutions was tested (Zukin, 1984). The comparisons drawn here must be considered very tentative because of the different survey technique but, more importantly, because the question format varies. In the first place, only two of the institutions are identified with exactly the same labels -"newspapers" and "television news." Three others are close -- "labor unions," "your local government," and "church/organized religious." Another three can be broadly construed for comparative purposes -- "Rutgers University," "large corporations," and "New Jersey state government" -- while another three are not at all comparable -"local schools," "the national government", and "New Jersey political parties."

The Eagleton Poll questions also varied the rating scheme, asking respondents if they had "a lot of," "some," or "not very much" confidence in the institutions. Comparisons of actual percentages or weighted scores for the two state samples must indeed be very tentative. Still, a comparison of relative rankings (based on weighted scores for the New Jersey data derived in the same way as for the Arkansas data) seems warranted and, as it happens, raises some very provocative questions. Very similar to Arkansans, New Jerseyans indicated greater confidence in religious institutions, mass media, and educational institutions. ${ }^{7}$ Governmental institutions constituted a distinct second tier and then labor unions, large corporations, and political parties at the bottom.

New Jerseyans seem to have somewhat more confidence in the mass media than Arkansans. The weighted scores -- 57 for television news and 53 for newspapers -- are not drastically different, but from a relative standpoint, the media belong to a top tier along with religion and education. 8 Arkansans, however, have a distinctive top tier made up of religion, education, and, shall we say, "altruistic" 


\section{Robert L. Savage and William R. Darden}

economic institutions (medicine, banks); the mass media clearly fall into a second tier into which particular governmental institutions may climb from time to time.

Beyond these patterns, mostly similar, Arkansans and New Jerseyans also are alike in the relative stability of their institutional "pecking order" across time. The Eagleton Poll had conducted earlier surveys in 1974 and 1978. Of the nine institutions common to all three surveys, seven of them are no more than two ranks different on any pair of surveys. Since the New Jersey polls are farther apart in time than the Arkansas polls, the stability is all the more striking.

Relative stability does not necessarily mean a lack of volatility, however. Recall that Arkansans exhibited a different pattern from national samples in overall assessments for confidence with Arkansans bottoming out in 1984 and nationwide Americans are becoming at least a little more positive at the same time. Jew Jerseyans, to the contrary, exhibited considerably more confidence in 1978 following the dismal Watergate crisis year of 1974, and in 1984 they have fallen to levels of confidence generally not much higher than 1974 . Some very different dynamics in public perceptions of institutions are almost certainly occurring across the American states, whether those institutions are local, statewide, or national in scope.

\section{The Same Song or a Different Tune? A Concluding Observation}

Savage and Blair (1982: 14) concluded that "Arkansans are neither wholly sour and suspicious nor wholly trusting and confident in their assessments." That remains the case. On the other hand, as argued there, those assessments may change as events and individuals reshape institutions, however, gradually. Certainly, this is the case with the somewhat stronger confidence that Arkansans exhibit for the Office of the Governor and oil companies in 1984. Similar forces may be at work for such changes as occurred with utilities and local governments even though they are not immediately apparent. ${ }^{9}$

Yet, relative judgments of institutions are unlikely to exhibit drastic changes over short periods of time. Moreover, with slight variations, there may well be a "pecking order" of institutions that has universal application across the United States and, within it, states and locales. Still, neither the sufficiency of existing data nor the sophistication of present theoretical explanation warrant much confidence in the ability to predict popular perceptions of institutions.

\section{Endnotes}

1See, e.g., "Public More Trusting?" (1983); Lipset and Schneider (1983); Gergen (1984); and a report of a New York Times-CBS News Poll in "Faith in Government" (1984).

2See generally, Britton and Savage (1981); and more specifically, Savage and Britton (1980).

3The results of this 1982 survey have been reported in various ways but those analyses that touch upon the institutional confidence findings are Savage and Blair (1982, 1984).

4See Savage and Blair (1982) for an explanation of these changes.

5On AHRP and its survey process, see Darden (1982). 


\section{Keceni Trends in Institutional Confidence}

6Note, however, a small but consistent tendency across all institutions for increased lack of response.

7Zukin (1984) rates educational institutions above mass media based on larger numbers of respondents indicating "a lot of" confidence. However, considerably larger number of "don't know" responses were given for educational intstitutions than for the mass media which affects the weighted scores considerably. In either case, the differences between the two categories of institutions is not great.

8Ironically, television news in New Jersey came from stations all located outside the state. In Arkansas it is precisely those regions which are more dependent upon out-of-state television stations that have the lowest levels of confidence in televisions news; see Savage and Blair (1984)

9 Of course, such changes may also be the product of sampling errors or simply the sum of random errors.

\section{References}

Britton, C.R., and Savage, R.L. (1981). Popular Perceptions of Banks among Arkansans: Explorations in Institutional Imagery. Fayetteville: Bureau of Business and Economic Research, University of Arkansas.

Darden, W.R. (1982). "Center for Marketing Research and Modeling: From AHRP to Where?" Arkansas Business and Economic Review, 15, 3: 23-25.

"Faith in Government Reaches High for Decade, Poll Says; Tax Rise Seen." (1984). Arkansas Gazette, November 19.

Gergen, D. (1984). "The Message to the Media," Public Opinion, 7 (April/May): 5-8.

Lipset, S.M., and Schneider, W. (1983). The Confidence Gap: Business, Labor, and Government in the Public Mind. New York: Free Press.

"Public More Trusting?" (1983). ISR Newsletter (Autumn): 2, 5.

Savage, R.L., and Blair, D.D. (1982). "Arkansans and Their Institutions The Questions of Public Confidence Again," Arkansas Business and Economic Review, 15, 3 (1982): 10-14.

Savage, R.L. and Blair, D.D. (1984). "Regionalism and Political Opinion in Arkansas: An Exploratory Survey," Arkansas Political Science Journal, 5: 59-85.

Savage, R.L., and Britton, C.R. (1980). "The Question of Public Confidence: Arkansas and the Nation," Arkansas Business and Economic Review, 13 (Winter): 20-23.

Shaver, P. (1980). "The Public Distrust," Psychology Today, 14 (October): 44-46.

Zukin, C. (1984). "Confidence in Institutions and Organizations Dips," news release from the Eagleton Institute of Politics, Rutgers University, New Brunswick, New Jersey, April 1. 
Robert L. Savage and William R. Darden

Table 1

Institutional confidence: 1980,1982 , and 1984

\% Who Indicate: *

Institution

A great deal Only some Hardly any No Year of confidence confidence confidence Response

\begin{tabular}{|c|c|c|c|c|}
\hline Churches & $\begin{array}{l}1982 \\
1984\end{array}$ & $\begin{array}{l}63.1 \\
64.9\end{array}$ & $\begin{array}{l}25.4 \\
27.0\end{array}$ & $\begin{array}{l}5.9 \\
6.8\end{array}$ \\
\hline Higher Education & $\begin{array}{l}1980 \\
1982 \\
1984\end{array}$ & $\begin{array}{l}47.1 \\
46.3 \\
44.7\end{array}$ & $\begin{array}{l}47.0 \\
45.5 \\
48.6\end{array}$ & $\begin{array}{l}5.3 \\
6.9 \\
4.4\end{array}$ \\
\hline Television News & $\begin{array}{l}1980 \\
1982 \\
1984\end{array}$ & $\begin{array}{l}24.3 \\
20.5 \\
17.4\end{array}$ & $\begin{array}{l}63.4 \\
60.8 \\
62.7\end{array}$ & $\begin{array}{l}11.5 \\
17.6 \\
17.7\end{array}$ \\
\hline Newspapers & $\begin{array}{l}1982 \\
1984\end{array}$ & $\begin{array}{l}16.1 \\
12.8\end{array}$ & $\begin{array}{l}66.2 \\
71.7\end{array}$ & $\begin{array}{l}17.0 \\
14.1\end{array}$ \\
\hline Medicine & $\begin{array}{l}1980 \\
1982 \\
1984\end{array}$ & $\begin{array}{l}51.1 \\
50.7 \\
51.2\end{array}$ & $\begin{array}{l}42.9 \\
43.8 \\
43.4\end{array}$ & $\begin{array}{l}4.8 \\
5.0 \\
3.0\end{array}$ \\
\hline Banks & $\begin{array}{l}1980 \\
1982 \\
1984\end{array}$ & $\begin{array}{l}50.7 \\
48.8 \\
46.8\end{array}$ & $\begin{array}{l}42.0 \\
44.0 \\
46.6\end{array}$ & $\begin{array}{l}6.4 \\
6.1 \\
5.2\end{array}$ \\
\hline Savings \& Loans & 1980 & 44.0 & 48.6 & 6.4 \\
\hline Organized Labor & $\begin{array}{l}1980 \\
1982 \\
1984\end{array}$ & $\begin{array}{r}10.8 \\
7.8 \\
8.7\end{array}$ & $\begin{array}{l}44.3 \\
40.7 \\
41.4\end{array}$ & $\begin{array}{l}44.2 \\
50.5 \\
47.0\end{array}$ \\
\hline $\begin{array}{l}\text { Electric Utilities } \\
\text { Utilities }\end{array}$ & $\begin{array}{l}1980 \\
1982 \\
1984\end{array}$ & $\begin{array}{r}18.1 \\
7.8 \\
13.9\end{array}$ & $\begin{array}{l}46.8 \\
44.0 \\
51.2\end{array}$ & $\begin{array}{l}34.3 \\
47.4 \\
32.9\end{array}$ \\
\hline Oil Companies & $\begin{array}{l}1980 \\
1982 \\
1984\end{array}$ & $\begin{array}{l}8.0 \\
5.0 \\
5.6\end{array}$ & $\begin{array}{l}26.1 \\
36.3 \\
47.1\end{array}$ & $\begin{array}{l}64.9 \\
57.6 \\
45.1\end{array}$ \\
\hline Local Government & $\begin{array}{l}1982 \\
1984\end{array}$ & $\begin{array}{r}15.3 \\
9.8\end{array}$ & $\begin{array}{l}62.5 \\
60.6\end{array}$ & $\begin{array}{l}21.4 \\
27.7\end{array}$ \\
\hline State Legislature & $\begin{array}{l}1980 \\
1982 \\
1984\end{array}$ & $\begin{array}{l}7.2 \\
7.5 \\
6.1\end{array}$ & $\begin{array}{l}60.4 \\
65.2 \\
63.2\end{array}$ & $\begin{array}{l}31.2 \\
26.6 \\
29.2\end{array}$ \\
\hline
\end{tabular}




\section{Reęnt Trends in Institutional Confidence}

$\begin{array}{llllll}\text { Governor's Office } & 1980 & 14.3 & 57.0 & 28.2 & 0.5 \\ \text { Office of the } & 1982 & 13.2 & 51.4 & 35.0 & 0.4 \\ \text { Governor } & 1984 & 16.3 & 59.0 & 22.9 & 1.9\end{array}$

${ }^{*}$ The number of respondents in the surveys are 609,523 , and 541 for 1980 , 1982, and 1984 respectively. 
Robert L. Savage and William R. Uarden

Table 2

The Institutions Ranked: 1982 and 1984

1982

1984

Institution

Rank

Score

Rank

Score

Churches

1

81

1

78

Medicine

2

73

2

73

Banks

8

71

8

70

Higher Education

4

69

4

69

Television News

5

51

49

Newspaper

6

49

49

Local Government

7

47

Office of the Governor

9

34

46

State Legislature

8

40

38

Utilities

10

30

40

Organized Labor

11

28

11

29

Oil Companies

12

23

12

29 